\title{
Variabilidade de Isolados de Alternaria brassicicola no Estado de Pernambuco
}

\author{
Sami J. Michereff ${ }^{1 *}$, Marissônia A. Noronha ${ }^{1}$, Otacílio M. Rocha $\mathbf{J r}^{1}$, Jearbes A. Silva ${ }^{1}$ \& \\ Eduardo S.G. Mizubuti ${ }^{*}$ \\ ${ }^{1}$ Área de Fitossanidade, Departamento de Agronomia, Universidade Federal Rural de Pernambuco, CEP 52171-900, Recife, PE, \\ e-mail: sami@ufrpe.br; ${ }^{2}$ Departamento de Fitopatologia, Universidade Federal de Viçosa, CEP 36571-000, Viçosa, MG, e-mail: \\ mizubuti@ufv.br
}

(Aceito para publicação em 21/08/2003)

Autor para correspondência: Sami J. Michereff

MICHEREFF, S.J., NORONHA, M.A., ROCHA JR., O.M., SILVA, J.A. \& MIZUBUTI, E.S.G. Variabilidade de isolados de Alternaria brassicicola no Estado de Pernambuco. Fitopatologia Brasileira 28:656-663 2003.

\section{RESUMO}

A variabilidade de 38 isolados de Alternaria brassicicola foi estimada com base em variáveis relacionadas ao desenvolvimento da alternariose e à fisiologia do patógeno. Os isolados foram coletados de cultivos comerciais de crucíferas do Estado de Pernambuco. Cada isolado foi inoculado em plantas de repolho (Brassica oleracea var. capitata), cv. Midori, com 40 dias, em casa de vegetação e os seguintes componentes epidemiológicos foram medidos: período de incubação (PI), severidade da doença (SEV) aos dez dias após a inoculação, taxa de progresso da doença (TPD) e área abaixo da curva de progresso da doença (AACPD). Cada isolado foi também avaliado quanto à taxa de crescimento micelial (TCM), esporulação (ESP), germinação de conídios (GER) e sensibilidade ao fungicida iprodione (ICM).
Constatou-se grande variabilidade quanto às variáveis medidas. Não houve efeito significativo de hospedeiro do qual os isolados foram obtidos e a variabilidade entre isolados de uma hospedeira foi, em geral, maior que a variância residual; à exceção para as variáveis PI e GER. Não foram verificadas correlações significativas $(P=0,05)$ das variáveis associadas à doença (PI, SEV, TPD e AACPD) com as demais variáveis. A análise da distancia Euclidiana por UPGMA não permitiu a separação dos 38 isolados do patógeno em grupos de similaridade, o que sugere variabilidade nas populações de $A$. brassicicola.

Palavras-chave adicionais: alternariose, crucíferas, componentes epidemiológicos, sensibilidade a iprodione.

\begin{abstract}
Variability of Alternaria brassicicola strains in the State of Pernambuco, Brazil

The variability of 38 isolates of Alternaria brassicicola was estimated based on disease development and pathogen physiology related variables. Forty-day-old cabbage (Brassica oleracea var. capitata) plants cv. Midori, under greenhouse conditions with isolates of A. brassicicola collected from crucifer commercial fields in Pernambuco, Brazil, were inoculated on . Epidemiological components such as incubation period (IP), disease severity ten days after inoculation (SEV), disease progress rate (DPR) and the area under the disease progress curve (AUDPC) were analyzed. Additionaly, the

mycelium growth rate (MGR), spore production (SPO), conidium germination (GER), and sensitivity to iprodione (MGI) were also measured. Alternaria brassicicola isolates were highly variable. The host of origin was of significant effect. Variances due to isolates within a particular host were generally higher than residual variance, except when analyzing PI and GER. There were no significant correlations $(\mathrm{P}=0.05)$ between disease-related variables (IP, SEV, DPR, and AUDPC) and the other variables. Cluster analyses based on UPGMA using Euclidean distance did not provide any evidence of cluster, which suggests a highly variable population of $A$. brassicicola associated with crucifers in Pernambuco.
\end{abstract}

\section{INTRODUÇÃO}

O Estado de Pernambuco é um dos principais produtores de crucíferas no Nordeste brasileiro. Apesar de bem adptadas às condições edafo-climáticas da região Agreste, onde se concentra a maioria das áreas de cultivo, as crucíferas têm baixa produtividade, atribuída, dentre outros fatores, à ocorrência de doenças (IPA/CEAGEPE/EMATER-PE, 1997).

A alternariose, causada principalmente por Alternaria brassicicola (Schwein.) Wiltsh. e Alternaria brassicae (Berk.)

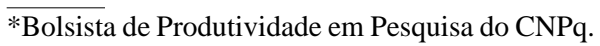

Sacc., é considerada a doença fúngica mais comum e destrutiva das crucíferas mundialmente (Verma \& Saharam, 1994; Maringoni, 1997). Em levantamentos efetuados nas safras 1997 e 1998, Azevedo et al. (2000) constataram a ocorrência de alternariose em $95 \%$ dos plantios de repolho (Brassica oleracea var. capitata L.) do Agreste de Pernambuco, com a predominância de $A$. brassicicola como agente patogênico. A alternariose causa danos nas fases de sementeira e planta adulta das crucíferas, resultando em reduções consideráveis na produtividade e na qualidade dos produtos. Os sintomas da doença se caracterizam por lesões necróticas circulares, marrom-escuras ou pretas, com anéis concêntricos, onde se 
encontram os conídios e conidióforos do fungo. As lesões causadas por A. brassicicola são menores e mais escuras que as causadas por A. brassicae (Maringoni, 1997). Os restos culturais e as sementes infestadas constituem as fontes principais de inóculo primário de A. brassicicola e os conídios se dispersam de forma rápida principalmente em condições de alta umidade e vento (Verma \& Saharam, 1994). Em Pernambuco, o controle da alternariose baseia-se em pulverizações, preventivamente ou após o aparecimento dos primeiros sintomas, com fungicidas a base de clorotalonil, mancozeb ou oxicloreto de cobre (Azevedo et al., 2000).

Várias espécies da família Cruciferae são cultivadas e possuem importância comercial em Pernambuco e em outros estados brasileiros. Comumente, são encontradas várias espécies sendo cultivadas numa mesma propriedade ou em áreas vizinhas (IPA/CEAGEPE/EMATER-PE, 1997), constituindo o inóculo inicial de epidemias de alternariose. No entanto, é possível que existam variações quanto à suscetibilidade das espécies hospedeiras cultivadas e que esta variação esteja associada com a variabilidade de características fisiológicas, morfológicas e patogênicas de importância epidemiológica (Rotem, 1994).

Conhecer a variabilidade das populações de fitopatógenos é útil no desenvolvimento de estratégias de controle de doenças de plantas (Milgroom, 2001, McDonald \& Linde, 2002a). Embora os tipos de variabilidade mais estudadas em populações de patógenos sejam adaptação a diferentes genótipos do hospedeiro e resposta a fungicidas, estudos envolvendo a biologia do patógeno e os componentes epidemiológicos da doença podem constituir importantes instrumentos de investigação (Brown, 1998). Do ponto de vista evolutivo, a variabilidade genética das populações é importante por determinar o potencial de adaptação do organismo às condições adversas. Do ponto de vista epidemiológico, a variabilidade patogênica tem implicações diretas no manejo da doença. Por exemplo, a maior agressividade de isolados de um patógeno implica em maior consumo de fungicidas (Kato et al., 1997) ou na revisão de estratégias de programas de melhoramento visando resistência à doença (McDonald \& Linde, 2002b).

Apesar da importância da alternariose para o estado de Pernambuco, até o momento inexistem estudos sobre a variabilidade do patógeno, motivo pelo qual o objetivo deste trabalho foi investigar a variabilidade de isolados de $A$. brassicicola provenientes de áreas de plantio de crucíferas da região Agreste, com base nos componentes epidemiológicos, características fisiológicas e sensibilidade ao fungicida iprodione.

\section{MATERIALEMÉTODOS}

\section{Obtenção dos isolados de Alternaria brassicicola}

Foram utilizados 38 isolados de $A$. brassicicola, obtidos de folhas de crucíferas com sintomas de alternariose, coletadas em diferentes áreas de plantio da região Agreste de Pernambuco durante o ano de 2000 (Tabela 1). Somente A. brassicicola foi constatada como agente da alternariose nas áreas de plantio.
Para obtenção dos isolados, as folhas com sintomas foram colocadas em câmara úmida, constituída de caixa tipo gerbox com esponja umedecida em água destilada sobreposta por tela plástica, e mantida à temperatura de $25 \pm 2{ }^{\circ} \mathrm{C}$ sob alternância luminosa ( $12 \mathrm{~h}$ claro/ $12 \mathrm{~h}$ escuro). Após três dias, as estruturas do fungo foram transferidas para placas de Petri contendo meio BDA suplementado com $0,01 \%$ de tetraciclina. Posteriormente, foram efetuadas preparações microscópicas das estruturas do fungo isolado, visando a confirmação da espécie A. brassicicola, conforme as descrições de Ellis (1971). As estruturas do fungo foram transferidas para tubos de ensaio contendo BDA e depois de cinco dias mantidas à temperatura de $5^{\circ} \mathrm{C}$.

\section{Variabilidade dos isolados de Alternaria brassicicola baseada em componentes epidemiológicos}

O inóculo de A. brassicicola foi multiplicado por dez dias em placas de Petri contendo meio BDA e incubadas à temperatura de $25 \pm 2{ }^{\circ} \mathrm{C}$ sob alternância luminosa ( $12 \mathrm{~h}$ claro/ $12 \mathrm{~h}$ escuro). Na preparação do inóculo, foram adicionados 20 $\mathrm{ml}$ de água destilada esterilizada em cada placa, efetuada a raspagem das colônias com escova de cerdas macias e filtragem em camada dupla de gaze esterilizada, para a posterior determinação da concentração de conídios com o auxílio de hemacitômetro. Todos os isolados apresentaram viabilidade dos conídios superior a $85 \%$. A inoculação foi efetuada em plantas de repolho, cv. "Midori", com 40 dias de idade e mantidas em casa de vegetação. Os talos das folhas foram marcadas com caneta de retroprojetor e a parte aérea de cada planta foi inoculada com atomização de $5 \mathrm{ml}$ da suspensão de 1x $10^{4}$ conídios $/ \mathrm{ml}$, de cada isolado de A. brassicicola, com o auxílio de atomizador DeVilbiss. Após a inoculação, as plantas foram mantidas em câmara úmida por $36 \mathrm{~h}$, constituída de sacos de polietileno umedecidos, e posteriormente em casa de vegetação. Durante o período de execução do experimento, a temperatura na casa-de-vegetação foi de $28,3 \pm 3,2{ }^{\circ} \mathrm{C}$ e a umidade relativa de $69,4 \pm 6,1 \%$.

As avaliações foram realizadas diariamente, até dez dias depois da inoculação, quanto à presença e severidade dos sintomas de alternariose nas folhas marcadas. Os isolados foram caracterizados em relação aos seguintes componentes epidemiológicos: período de incubação (PI), determinado pelo número de h entre a inoculação e o aparecimento dos sintomas (Parlevliet, 1979); severidade da doença (SEV), determinada em todas as folhas da planta aos dez dias após a inoculação, pela porcentagem de área foliar lesionada, com o auxílio de escala diagramática (Conn et al., 1990) e cálculo da média por planta; taxa de progresso da doença (TPD), estimada pelo parâmetro "b" da equação de regressão linear simples, tendo o tempo (em dias) após a inoculação como variável independente e a proporção da severidade diária da doença como variável dependente (Campbell \& Madden, 1990); área abaixo da curva de progresso da doença (AACPD), calculada pela expressão: AACPD $=\Sigma\left(y_{i}+y_{i+1}\right) / 2 . d_{t i}$, onde $y_{i}$ e $y_{i+1}$ são os valores de severidade observados em duas avaliações consecutivas e $\mathrm{d}_{\mathrm{ti}}$ o intervalo entre as avaliações (Shaner \& Finney, 1977). 


\section{S.J. Michereff et al.}

O delineamento experimental foi inteiramente casualizado, com oito repetições, sendo cada repetição constituída por uma planta de repolho.

\section{Variabilidade dos isolados de Alternaria brassicicola baseada em características fisiológicas}

Cada isolado do patógeno foi avaliado quanto à taxa de crescimento micelial (TCM), esporulação (ESP) e germinação de conídios (GER). Para obtenção da TCM, discos de meio BDA com 6 mm de diâmetro, contendo crescimento dos isolados de A. brassicicola com oito dias de idade foram transferidos para o centro de placas de Petri contendo BDA. As placas foram mantidas a $25 \pm 2{ }^{\circ} \mathrm{C}$, sob alternância luminosa ( $12 \mathrm{~h}$ claro/ $12 \mathrm{~h}$ escuro). $\mathrm{O}$ delineamento experimental foi inteiramente casualizado, com seis repetições, sendo cada repetição constituída por uma placa. O crescimento micelial de cada isolado foi avaliado diariamente, até dez dias de incubação, pela mensuração do diâmetro da colônia em dois sentidos diametralmente opostos e cálculo da média por placa. Os valores de crescimento micelial foram ajustados ao modelo de regressão linear simples, tendo tempo (em dias) como variável independente e crescimento micelial (em $\mathrm{mm}$ ) como variável dependente. A TCM (mm/dia) foi estimada pelo parâmetro " $b$ " da equação de regressão.

A ESP foi avaliada aos dez dias de incubação, pela adição de $20 \mathrm{ml}$ de água destilada esterilizada em cada placa utilizada para avaliação do crescimento micelial, raspagem das colônias com escovas de cerdas macias e peneiramento em camada dupla de gaze, para a posterior estimativa da concentração de conídios (conídios/ml) com o auxílio de hemacitômetro. Foram efetuadas três contagens de cada placa (suspensão), obtendo-se a média.

$\mathrm{Na}$ avaliação da GER foi utilizado o método da deposição de gota sobre lâmina (Dhingra \& Sinclair, 1995), sendo utilizada a suspensão de conídios obtida para avaliação da esporulação. Após a homogeneização da suspensão de conídios por agitação mecânica em vortex, foram retirados 0,2 ml e depositados sobre uma lâmina de vidro, acondicionada em câmara úmida, constituída de placa de Petri com três camadas de papel de filtro umedecido em água destilada. O conjunto foi mantido a $25 \pm 2{ }^{\circ} \mathrm{C}$ sob luminosidade contínua. Após $6 \mathrm{~h}$ de incubação, uma gota de azul de Aman foi depositada sobre a suspensão de conídios contida na lâmina, procedendo-se à contagem do número de conídios germinados e não germinados, em microscópio ótico. Foi considerado como conídio germinado aquele que apresentava o comprimento do tubo germinativo com pelo menos duas vezes sua maior largura. Para efeito de cálculo, foi obtida a média de 50 conídios em dois campos do microscópio por repetição, sob aumento de 40x, determinandose a porcentagem de germinação de conídios. O delineamento experimental foi inteiramente casualizado, com seis repetições, sendo cada repetição constituída por uma lâmina.

\section{Variabilidade de isolados de Alternaria brassicicola baseada na sensibilidade ao fungicida iprodione}

Na determinação da sensibilidade dos isolados de $A$. brassicicola a iprodione, foi utilizado o método do fungicida incorporado ao meio de cultura (Dhingra \& Sinclair, 1995). Discos de BDA com $6 \mathrm{~mm}$ de diâmetro, contando o crescimento dos isolados, foram transferidos para placas com BDA suplementado com 5 ppm de iprodione (Rovral ${ }^{\circledR}, 50 \%$ p.a.; Bayer Cropscience S.A., São Paulo, Brasil). A testemunha consistiu na transferência das estruturas dos isolados para placas com BDA, sem suplementação com o fungicida. As placas foram mantidas a $25 \pm 2{ }^{\circ} \mathrm{C}$, sob alternância luminosa. $\mathrm{O}$ delineamento experimental foi inteiramente casualizado, com seis repetições, sendo cada repetição constituída por uma placa. $\mathrm{O}$ crescimento micelial foi mensurado como descrito anteriormente. Considerando o crescimento máximo verificado na testemunha, foi calculada a porcentagem de inibição do crescimento micelial (ICM) na presença do fungicida.

\section{Análises dos dados}

As análises foram conduzidas em duas etapas: inicialmente, foi realizada a análise univariada, considerando cada variável separadamente. Posteriormente os dados foram submetidos à análise multivariada, considerando as variáveis em conjunto. Para as análises univariadas, os dados de PI, SEV, TPD, TCM, GER e ICM foram transformados em $\sqrt{x}$ e os dados de AACPD e ESP em log (x), para evitar violações das pressuposições da análise de variância. Considerando as variáveis isoladamente, os dados foram submetidos à análise de variância utilizando um modelo linear misto (fatores fixos e aleatórios) em esquema hierárquico ou aninhado ("nested") (Neter et al., 1990). A espécie hospedeira foi considerada como fator fixo e os isolados, aninhados dentro da espécie hospedeira de origem, foram considerados como amostras aleatórias da população de isolados de A. Brassicicola; portanto, um fator aleatório. $\mathrm{O}$ modelo utilizado foi: $y_{i j}=\mu+\alpha_{\mathrm{i}}+\mathrm{b}_{\mathrm{j}(\mathrm{i})}$; onde $\mu=$ média geral; $\alpha_{i}=$ é o efeito do fator espécie hospedeira (fixo) e $\mathrm{b}_{\mathrm{j}(\mathrm{i})}=$ efeito do fator isolado (aleatório) aninhado dentro de espécie hospedeira. Com este modelo é possível testar o efeito do hospedeiro de onde os isolados foram obtidos (hospedeiro de origem) bem como o percentual da variância devido à variabilidade da amostra de isolados de uma espécie hospedeira. As estimativas destes efeitos foram avaliadas por meio do Proc Mixed (Littell et al., 1996) do programa SAS ver 8.0. Adicionalmente, foi avaliada a correlação entre as variáveis relacionadas ao desenvolvimento da alternariose (PI, SEV, TPD e AACPD) com as variáveis fisiológicas e de sensibilidade ao fungicida iprodione. Para tal empregou-se a análise de correlação de Pearson (5\%).

Considerando o conjunto de variáveis - análise multivariada, empregou-se a análise de agrupamento (“Cluster”) baseado nos níveis de similaridade utilizando a distância Euclidiana estimada com base no algoritmo de UPGMA. Estas análises foram efetuadas com o auxílio do programa STATISTICA for Windows (StatSoft Inc., Tulsa - OK, USA, 2000).

\section{RESULTADOS}

Todos os 38 isolados de A. brassicicola foram pato- 
gênicos a plantas de repolho, cv. "Midori", ocasionando sintomas típicos de alternariose nas folhas. Observou-se variabilidade dos dados referentes às diferentes variáveis medidas (Tabela 1). Não houve diferença significativa quanto à origem dos isolados de diferentes espécies hospedeiras para todos os componentes epidemiológicos avaliados (Tabela 2).Isto é, a média do PI dos isolados de couve-chinesa (Brassica pekinnensis L.) não diferiu da média dos isolados de repolho, couve comum (Brassica oleracea var. acephala L.), couve-flor (Brassica oleracea var. botrytis L.) e brócolis (Brassica oleracea var. italica L.) Um considerável percentual da variância resultou de diferenças entre isolados de uma hospedeira. Os percentuais para as variáveis PI, SEV, AACPD e TPD foram 28,5\%; 53,5\%; 54,9\% e 55,0\% da variância total, respectivamente (Tabela 2). O PI da alternariose variou de 36,0 a 75,4 h, estando os valores referentes aos isolados AB-9, AB-11, AB-12, AB-17, AB-27 e AB-31 no limite inferior e ao isolado AB-8 no limite superior. Os valores de SEV variaram entre 4,1 e $38,9 \%$, os de TPD entre 0,35 e 4,21\% ao dia e os de AACPD entre 18,1 e 146,3 unidades, em todas as situações referentes aos isolados AB32 e AB-31, respectivamente. Foram constatadas correlações negativas significativas $(\mathrm{P}=0,05)$ de $\mathrm{PI} \operatorname{com} \mathrm{SEV}(\mathrm{r}=-0,67)$, TPD $(r=-0,5)$ e AACPD $(r=-0,68)$, assim como correlações positivas significativas $(\mathrm{P}=0,05)$ entre $\mathrm{SEV}, \mathrm{TPD}$ e AACPD $(\mathrm{r} \geq$ 0,98) (Tabela 3).

Para as características fisiológicas TCM, ESP e GER, não houve diferença significativa quanto aos hospedeiros de origem dos isolados. A variabilidade percentual em relação à variância total entre isolados de uma mesma espécie hospedeira foi de $68,8 \%$ para a variável TCM, 58,9\% para ESP e de $26,8 \%$ para GER (Tabela 2). Portanto, à exceção da variável GER, o componente de variância referente a isolados dentro de hospedeira foi superior à variância do erro. Não foram constatadas correlações significativas $(\mathrm{P}=0,05)$ entre as diferentes características fisiológicas dos isolados de $A$. brassicicola (Tabela 3).

Grande parte da variabilidade, $75,3 \%$, observada quanto à resistência ao fungicida iprodione (medida como ICM) foi devida à variação de isolado para isolado, dentro de uma mesma espécie hospedeira de origem (Tabela 2). Não houve diferença significativa para o fator espécie hospedeira. Os isolados AB19 e AB-20 apresentaram os maiores valores de ICM, indicando maior sensibilidade do crescimento micelial ao fungicida. Os isolados AB-28 e AB-21 evidenciaram a menor sensibilidade ao fungicida.

Não foram constatadas correlações significativas $(\mathrm{P}=0,05)$ das variáveis associadas à doença (PI, SEV, TPD e AACPD) com as demais variáveis (TCM, ESP, GER e ICM) (Tabela 3).

Utilizando o conjunto de variáveis avaliadas, a análise da distância Euclidiana por UPGMA não permitiu a separação dos isolados de A. brassicicola em grupos de similaridade (Figura 1), o que reforça a grande variabilidade entre isolados do patógeno e a não distinção quanto às espécies hospedeiras de origem.

\section{DISCUSSÃO}

Com base em componentes epidemiológicos e variáveis fisiológicas, constatou-se grande variabilidade entre isolados de A. brassicicola na região do Agreste Pernambucano. Diferentemente do uso de marcadores genéticos, geralmente seletivamente neutros, usados em muitos estudos, as variáveis utilizadas permitiram estabelecer relação mais direta entre variabilidade e implicações para o desenvolvimento da doença.

À exceção das variáveis PI (28,5\%) e GER (26,8\%), o maior percentual da variância total foi devido à variabilidade constatada entre isolados obtidos de uma mesma espécie hospedeira. $\mathrm{O}$ baixo percentual dos componentes de variância associados a PI e GER podem ter sido conseqüência da metodologia de quantificação. No caso de PI, foram tomadas medidas a intervalos diários, porém, haveria maior chance de detectar variação entre isolados se o PI fosse avaliado a intervalos mais freqüentes. Quanto a GER, é possível que no caso de patógenos que formam conídios multicelulares, como os de A. brassicicola, haja menor variabilidade quando a avaliação é baseada na formação/presença de tubo germinativo.

Em geral, houve baixa probabilidade de haver alta especificidade por hospedeiro. Uma das implicações deste fato seria quanto à dinâmica de inóculo de $A$. brassicicola na região. Aparentemente, as diferentes culturas de crucíferas podem atuar como eficientes fontes de inóculo para novos plantios. Estudos de inoculação cruzada, onde todos os isolados são inoculados em todas as espécies hospedeiras, são necessários para confirmar se o inóculo proveniente de campos ou de restos culturais de uma espécie seriam igualmente adaptados quanto à patogenicidade e virulência em uma espécie distinta. Este conhecimento é potencialmente útil para delinear estratégias mais eficientes de controle da doença.

Considerando que a alternariose das crucíferas é uma doença policíclica (Verma \& Saharam, 1994; Azevedo et al., 2002), a velocidade da epidemia é influenciada pelo período de incubação (Hau \& Vallavieille-Pope, 1998). Portanto, as correlações negativas entre PI e as demais variáveis associadas à doença (SEV, TPD e AACPD) indicam que a quantidade de alternariose está inversamente relacionada ao tempo de início dos sintomas, semelhante ao relatado em outros patossistemas (Parlevliet, 1979; Hau \& Vallavieille-Pope, 1998; Paula et al., 2000). A ausência de correlações significativas entre TCM, ESP e GER dos isolados de A. brassicicola indica a independência entre essas variáveis e assemelha-se ao verificado em outros estudos (Griffin, 1994; Paula et al., 2000).

As variações na sensibilidade ao fungicida iprodione entre os isolados de A. brassicicola, verificadas neste estudo, confirmaram as observações de Hau \& Vallavieille-Pope (1998) de que entre isolados de um patógeno caracterizados por sua variabilidade patogênica podem ser definidas sub-populações em relação a sensibilidade a fungicidas. Fungos fitopatogênicos produtores de esporos assexuais multinucleados, como é o caso de A. brassicicola (Ellis, 1971), podem produzir micélio heterocariótico contendo núcleos sensíveis e resistentes ao 


\section{S.J. Michereff et al.}

TABELA 1 - Valores de componentes epidemiológicos, de características fisiológicas e de sensibilidade ao fungicida iprodione medidos para estimar a variabilidade de isolados de Alternaria brassicicola procedentes de diferentes áreas de plantio de crucíferas do Estado de Pernambuco

\begin{tabular}{|c|c|c|c|c|c|c|c|c|c|c|}
\hline \multirow[b]{2}{*}{ Isolado } & \multirow{2}{*}{$\begin{array}{c}\text { Origem } \\
\text { (município) }\end{array}$} & \multirow[b]{2}{*}{ Hospedeiro } & \multicolumn{4}{|c|}{ Componentes Epidemiólogicos } & \multicolumn{3}{|c|}{ Características Fisiológicas } & \multirow{2}{*}{$\begin{array}{c}\text { Iprodione } \\
\text { ICM }^{8} \\
(\%)\end{array}$} \\
\hline & & & $\begin{array}{l}P^{1} \\
\text { (h) }\end{array}$ & $\begin{array}{c}\text { SEV }^{2} \\
(\%)\end{array}$ & TPD $^{3}$ & $\mathrm{AACPD}^{4}$ & $\begin{array}{c}\mathrm{TCM}^{5} \\
\text { (mm/dia) }\end{array}$ & $\begin{array}{c}\text { ESP }^{6} \\
\left(\times 10^{5} \operatorname{con} / \mathrm{ml}\right)\end{array}$ & $\begin{array}{c}\text { GER }^{7} \\
(\%)\end{array}$ & \\
\hline AB-01 & Gravata & couve comum & $51,4^{9}$ & 9,3 & 0,87 & 33,8 & 0,81 & 7,2 & 87,7 & 30,2 \\
\hline AB-02 & Sairé & couve-flor & 60,0 & 6,7 & 0,59 & 24,8 & 0,73 & 8,6 & 90,2 & 42,0 \\
\hline AB-03 & Camocim & repolho & 51,4 & 18,7 & 2,05 & 66,6 & 0,81 & 5,5 & 94,5 & 46,6 \\
\hline AB-04 & Camocim & repolho & 54,9 & 10,1 & 0,93 & 36,8 & 0,69 & 10,6 & 89,9 & 33,4 \\
\hline $\mathrm{AB}-05$ & Camocim & couve-chinesa & 44,6 & 14,1 & 1,46 & 50,4 & 0,89 & 5,4 & 92,1 & 32,8 \\
\hline AB-06 & Vitória & couve-flor & 41,1 & 10,1 & 0,90 & 38,6 & 0,88 & 8,1 & 84,7 & 57,6 \\
\hline AB-07 & Bezerros & couve-flor & 37,1 & 18,9 & 1,92 & 74,7 & 0,90 & 8,8 & 92,3 & 56,3 \\
\hline AB-08 & Bezerros & repolho & 75,4 & 5,6 & 0,61 & 21,3 & 0,77 & 12,3 & 94,3 & 57,6 \\
\hline AB-09 & Chã Grande & couve-flor & 36,0 & 23,7 & 2,66 & 84,6 & 0,73 & 14,1 & 91,2 & 40,3 \\
\hline AB-10 & Camocim & couve-chinesa & 49,7 & 9,9 & 0,97 & 34,4 & 0,86 & 18,4 & 85,0 & 60,8 \\
\hline AB-11 & Bezerros & couve-flor & 36,0 & 23,3 & 2,50 & 78,7 & 0,74 & 11,4 & 94,0 & 38,1 \\
\hline AB-12 & Camocim & repolho & 36,0 & 19,4 & 2,13 & 67,8 & 0,41 & 6,6 & 92,8 & 47,0 \\
\hline $\mathrm{AB}-13$ & Camocim & couve-chinesa & 41,1 & 15,7 & 1,69 & 50,9 & 0,52 & 10,5 & 89,3 & 46,4 \\
\hline AB-14 & Recife & repolho & 39,4 & 15,3 & 1,65 & 56,3 & 0,64 & 12,9 & 88,5 & 42,5 \\
\hline AB-15 & Sairé & couve-chinesa & 41,1 & 13,1 & 1,09 & 44,3 & 0,84 & 13,1 & 89,3 & 48,3 \\
\hline AB-16 & Camocim & repolho & 53,4 & 7,3 & 0,69 & 29,4 & 0,51 & 12,1 & 90,8 & 46,0 \\
\hline AB-17 & Camocim & couve-flor & 36,0 & 22,9 & 2,44 & 82,8 & 0,84 & 12,6 & 97,3 & 46,3 \\
\hline AB-18 & Camocim & brócolis & 39,4 & 16,9 & 1,80 & 64,3 & 0,59 & 14,4 & 87,2 & 45,8 \\
\hline AB-19 & São Joaquim & repolho & 42,9 & 14,4 & 1,53 & 53,4 & 0,70 & 12,6 & 85,7 & 82,8 \\
\hline AB-20 & São Joaquim & repolho & 46,3 & 10,7 & 1,12 & 41,2 & 0,73 & 10,2 & 95,6 & 81,8 \\
\hline $\mathrm{AB}-21$ & Camocim & couve comum & 39,4 & 16,6 & 1,75 & 53,2 & 0,51 & 9,5 & 94,2 & 4,3 \\
\hline AB-22 & Camocim & repolho & 65,1 & 7,8 & 0,71 & 28,0 & 0,78 & 12,8 & 94,8 & 82,7 \\
\hline AB-23 & Chã Grande & brócolis & 37,7 & 15,7 & 1,74 & 60,8 & 0,77 & 9,7 & 93,5 & 66,7 \\
\hline AB-24 & Camocim & couve comum & 44,6 & 13,9 & 1,48 & 49,7 & 0,70 & 10,8 & 92,7 & 37,1 \\
\hline $\mathrm{AB}-25$ & Vitória & couve comum & 39,4 & 19,6 & 2,10 & 75,5 & 0,79 & 8,4 & 93,3 & 51,7 \\
\hline AB-26 & Vitória & couve-flor & 42,9 & 34,3 & 3,88 & 113,5 & 0,83 & 11,4 & 94,8 & 52,6 \\
\hline AB-27 & Gravatá & couve comum & 36,0 & 24,0 & 2,58 & 82,9 & 0,79 & 10,6 & 92,0 & 58,5 \\
\hline AB-28 & Vitória & brócolis & 58,3 & 9,9 & 1,03 & 38,4 & 0,79 & 12,5 & 88,6 & 4,6 \\
\hline AB-29 & Bezerros & repolho & 48,0 & 18,7 & 2,14 & 64,5 & 0,88 & 7,6 & 92,2 & 61,5 \\
\hline AB-30 & Gravatá & couve comum & 42,9 & 10,7 & 1,12 & 43,0 & 0,74 & 12,7 & 93,2 & 41,6 \\
\hline AB-31 & Vitória & couve-flor & 36,0 & 38,9 & 4,21 & 146,3 & 0,91 & 10,8 & 93,6 & 42,9 \\
\hline AB-32 & Camocim & repolho & 68,6 & 4,1 & 0,35 & 18,1 & 0,96 & 13,2 & 93,5 & 43,4 \\
\hline AB-33 & Sairé & couve-flor & 44,5 & 8,6 & 0,64 & 36,4 & 0,81 & 15,0 & 91,2 & 28,0 \\
\hline AB-34 & Camocim & couve comum & 51,4 & 11,9 & 1,12 & 41,1 & 0,78 & 10,7 & 90,2 & 26,9 \\
\hline AB-35 & Camocim & brócolis & 46,3 & 12,9 & 1,31 & 45,6 & 0,75 & 12,5 & 90,5 & 29,1 \\
\hline AB-36 & São Joaquim & repolho & 51,4 & 9,9 & 1,04 & 34,6 & 0,86 & 12,1 & 93,0 & 39,4 \\
\hline AB-37 & Chã Grande & brócolis & 49,7 & 16,0 & 1,17 & 51,8 & 0,84 & 14,9 & 90,3 & 34,9 \\
\hline AB-38 & Chã Grande & couve comum & 48,0 & 12,0 & 1,70 & 42,1 & 0,84 & 10,7 & 96,2 & 53,1 \\
\hline
\end{tabular}

${ }^{1} \mathrm{PI}=$ período de incubação, determinado pelo número de horas entre a inoculação e o aparecimento dos sintomas (Parlevliet, 1979);

${ }^{2} \mathrm{SEV}$ = severidade da doença aos dez dias após a inoculação, estimada com o auxílio de escala diagramática (Conn et al., 1990);

${ }^{3} \mathrm{TPD}=$ taxa de progresso da doença, estimada pelo parâmetro "b" da equação de regressão linear simples, tendo o tempo (em dias) após a inoculação como variável independente e a proporção da severidade diária da doença como variável dependente (Campbell \& Madden, 1990);

${ }^{4} \mathrm{AACPD}=$ área abaixo da curva de progresso da doença, calculada conforme Shaner \& Finney (1977);

${ }^{5}$ TCM = taxa de crescimento micelial em meio BDA sob alternância luminosa, estimada pelo parâmetro "b" da equação de regressão linear simples, tendo o tempo (em dias) como variável independente, avaliada aos dez dias de incubação em meio BDA sob alternância luminosa;

${ }^{7}$ GER = germinação de conídios, avaliada pelo método da deposição de gota sobre lâmina (Dhingra \& Sinclair, 1995);

${ }^{8} \mathrm{ICM}=$ inibição do crescimento micelial por iprodione, determinado pelo método do fungicida incorporado ao meio de cultura (Dhingra \& Sinclair, 1995), considerando a concentração de 5 ppm;

${ }^{9}$ Dados originais.

fungicida. Esses heterocarions são capazes de crescer na presença ou ausência do fungicida e, portanto, capacitam o patógeno a manter núcleos resistentes e sensíveis na população e a se adaptar para qualquer pressão de seleção dentro do ambiente (Summers et al., 1984).

A presença de isolados de A. brassicicola com baixa sensibilidade ao iprodione é inesperada, pois esse fungicida não tem sido utilizado para o controle da alternariose das 
TABELA 2 - Estimativa de efeito médio do hospedeiro e dos componentes de variância para os fatores: isolados de Alternaria brassicicola dentro de hospedeiro e resíduo; para os componentes epidemiológicos e variáveis fisiológicas

\begin{tabular}{|c|c|c|c|c|c|c|c|c|}
\hline \multirow{2}{*}{ Fator de Variação } & \multicolumn{8}{|c|}{ Variáveis } \\
\hline & $\mathbf{P I}^{1}$ & SEV $^{2}$ & $\mathrm{AACPD}^{3}$ & TPD $^{4}$ & ESP $^{5}$ & TCM $^{6}$ & GER $^{7}$ & $\mathrm{ICM}^{8}$ \\
\hline HOSPEDEIRO & & & & & & & & \\
\hline $\begin{array}{l}\text { Valor de F } \\
\text { (Significância - Val or de P) }\end{array}$ & $\begin{array}{c}2,23 \\
(0,146)\end{array}$ & $\begin{array}{c}1,41 \\
(0,289)\end{array}$ & $\begin{array}{c}1,56 \\
(0,251)\end{array}$ & $\begin{array}{c}1,19 \\
(0,362)\end{array}$ & $\begin{array}{c}1,47 \\
(0,296)\end{array}$ & $\begin{array}{c}1,42 \\
(0,289)\end{array}$ & $\begin{array}{c}1,54 \\
(0,273)\end{array}$ & $\begin{array}{c}1,56 \\
(0,255)\end{array}$ \\
\hline $\begin{array}{l}\text { ISOLADO (HOSPEDEIRO) } \\
\text { Componente }{ }^{2} \mathrm{I}(\mathrm{H}) \\
\text { (Percentual) }\end{array}$ & $\begin{array}{c}0,219 \\
(28,5 \%)\end{array}$ & $\begin{array}{c}0,522 \\
(53,5 \%)\end{array}$ & $\begin{array}{c}0,129 \\
(54,9 \%)\end{array}$ & $\begin{array}{c}0,071 \\
(55 \%)\end{array}$ & $\begin{array}{c}0,089 \\
(58,9 \%)\end{array}$ & $\begin{array}{c}0,006 \\
(68,8 \%)\end{array}$ & $\begin{array}{c}0,037 \\
(26,8 \%)\end{array}$ & $\begin{array}{c}2,270 \\
(75,3 \%)\end{array}$ \\
\hline $\begin{array}{l}\text { RESÍDUO } \\
\text { Componente }{ }^{2} \\
\text { (Percentual) }\end{array}$ & $\begin{array}{c}0,548 \\
(71,5 \%)\end{array}$ & $\begin{array}{c}0,455 \\
(46,5 \%)\end{array}$ & $\begin{array}{c}0,106 \\
(45,1 \%)\end{array}$ & $\begin{array}{l}0,058 \\
(45 \%)\end{array}$ & $\begin{array}{c}0,061 \\
(41,1 \%)\end{array}$ & $\begin{array}{l}0,003 \\
(31,2 \%)\end{array}$ & $\begin{array}{c}0,101 \\
(63,2 \%)\end{array}$ & $\begin{array}{c}0,744 \\
(24,7 \%)\end{array}$ \\
\hline
\end{tabular}

${ }^{1} \mathrm{PI}=$ período de incubação, determinado pelo número de h entre a inoculação e o aparecimento dos sintomas.

${ }^{2} \mathrm{SEV}=$ severidade da doença aos 10 dias após a inoculação, estimada com o auxílio de escala diagramática.

${ }^{3} \mathrm{TPD}=$ taxa de progresso da doença, estimada pelo parâmetro "b" da equação de regressão linear simples, tendo o tempo (em dias) após a inoculação como variável independente e a proporção da severidade diária da doença como variável dependente.

${ }^{4} \mathrm{AACPD}=$ área abaixo da curva de progresso da doença.

${ }^{5} \mathrm{TCM}=$ taxa de crescimento micelial em meio BDA sob alternância luminosa, estimada pelo parâmetro "b" da equação de regressão linear simples, tendo o tempo (em dias) como variável independente e crescimento micelial ( $\mathrm{mm}$ ) como variável dependente.

${ }^{6} \mathrm{ESP}=$ esporulação, avaliada aos 10 dias de incubação em meio BDA sob alternância luminosa.

${ }^{7} \mathrm{GER}=$ germinação de conídios, avaliada pelo método da deposição de gota sobre lâmina.

${ }^{8} \mathrm{ICM}=$ inibição do crescimento micelial por iprodione, determinado pelo método do fungicida incorporado ao meio de cultura, considerando a concentração de 5 ppm.

Dados originais. Para efeito de análise, os dados de PI, SEV, TPD, TCM, GER e ICM foram transformados em (x) ${ }^{1 / 2}$ e os dados de AACPD e ESP em $\log (\mathrm{x})$.

TABELA 3 - Matriz de correlação do período de incubação (PI), severidade (SEV), taxa de progresso da doença (TPD), área abaixo da curva de progresso da doença (AACPD), taxa de crescimento micelial (TCM), esporulação (ESP), germinação de conídios (GER) e sensibilidade ao fungicida iprodione (ICM) de isolados de Alternaria brassicicola procedentes de diferentes áreas de plantio de crucíferas do Estado de Pernambuco Número de observações (Tabela 1) $=38$

\begin{tabular}{|c|c|c|c|c|c|c|c|}
\hline Variável & $E$ & 空 & 定 & $\frac{2}{\dot{U}}$ & $\sum_{U}$ & 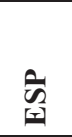 & 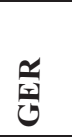 \\
\hline SEV & $-0,67^{*}$ & - & - & - & - & - & - \\
\hline TPD & $-0,65^{*}$ & $0,99 *$ & - & - & - & - & - \\
\hline AACPD & $-0,68^{*}$ & $0,99 *$ & $0,98^{*}$ & - & - & - & - \\
\hline $\mathrm{TCM}$ & 0,20 & 0,06 & 0,03 & 0,08 & - & - & - \\
\hline ESP & 0,12 & $-0,14$ & $-0,17$ & $-0,14$ & 0,05 & - & - \\
\hline GER & 0,10 & 0,17 & 0,20 & 0,16 & 0,18 & $\theta, 22$ & - \\
\hline ICM & 0,01 & 0,03 & 0,06 & 0,05 & 0,13 & 0,02 & 0,07 \\
\hline
\end{tabular}

*Coeficientes de correlacão de Pearson seguidos por asterisco são significativos a $\mathrm{P}=0,05$.

crucíferas em Pernambuco (Azevedo et al., 2000) e a acumulação de mutantes resistentes em populações fúngicas depende, entre outros fatores, da pressão de seleção exercida pela frequiência de aplicação do fungicida (Kendall \& Hollomon, 1998).

A ausência de correlações significativas das variáveis associadas à doença com as demais variáveis indica a pouca validade de características fisiológicas e da sensibilidade ao fungicida iprodione na detecção de variabilidade patogênica em populações de A. brassicicola, assemelhando-se ao constatado em outros estudos com esse patógeno (Changsri \& Weber, 1963; Campbell et al., 1968), apesar do esforço que tem sido dedicado ao estudo da variabilidade em fitopatógenos baseada em características outras que relacionadas à patogenicidade (Brown, 1998). Embora o surgimento de resistência ao iprodione possa implicar na redução da virulência dos isolados resistentes (Fuchs \& Waard, 1982), não foram verificadas correlações consistentes entre a velocidade de indução dos sintomas ou a intensidade da alternariose e a sensibilidade ao iprodione entre os isolados de A. brassicicola. Além disso, no presente estudo, a sensibilidade ao iprodione não esteve associada com a capacidade de crescimento micelial, esporulação ou germinação de conídios. Resultados diferentes foram obtidos por Huang \& Levy (1995) ao caracterizarem isolados de A. brassicicola resistentes ao iprodione, uma vez que naquele estudo a maioria dos isolados apresentou colônias menores que os isolados selvagens em meio BDA, assim como menor esporulação e intensidade da doença em folhas destacadas de brócolis.

A variabilidade entre os isolados de A. brassicicola, oriundos de diferentes áreas cultivadas com crucíferas em Pernambuco, ficou evidente pela não formação de grupos distintos na análise de agrupamento. A não-especificidade por hospedeiro de isolados do patógeno já fora relatada quando se utilizaram marcadores genéticos (RAPD) (Verma \& Saharam, 


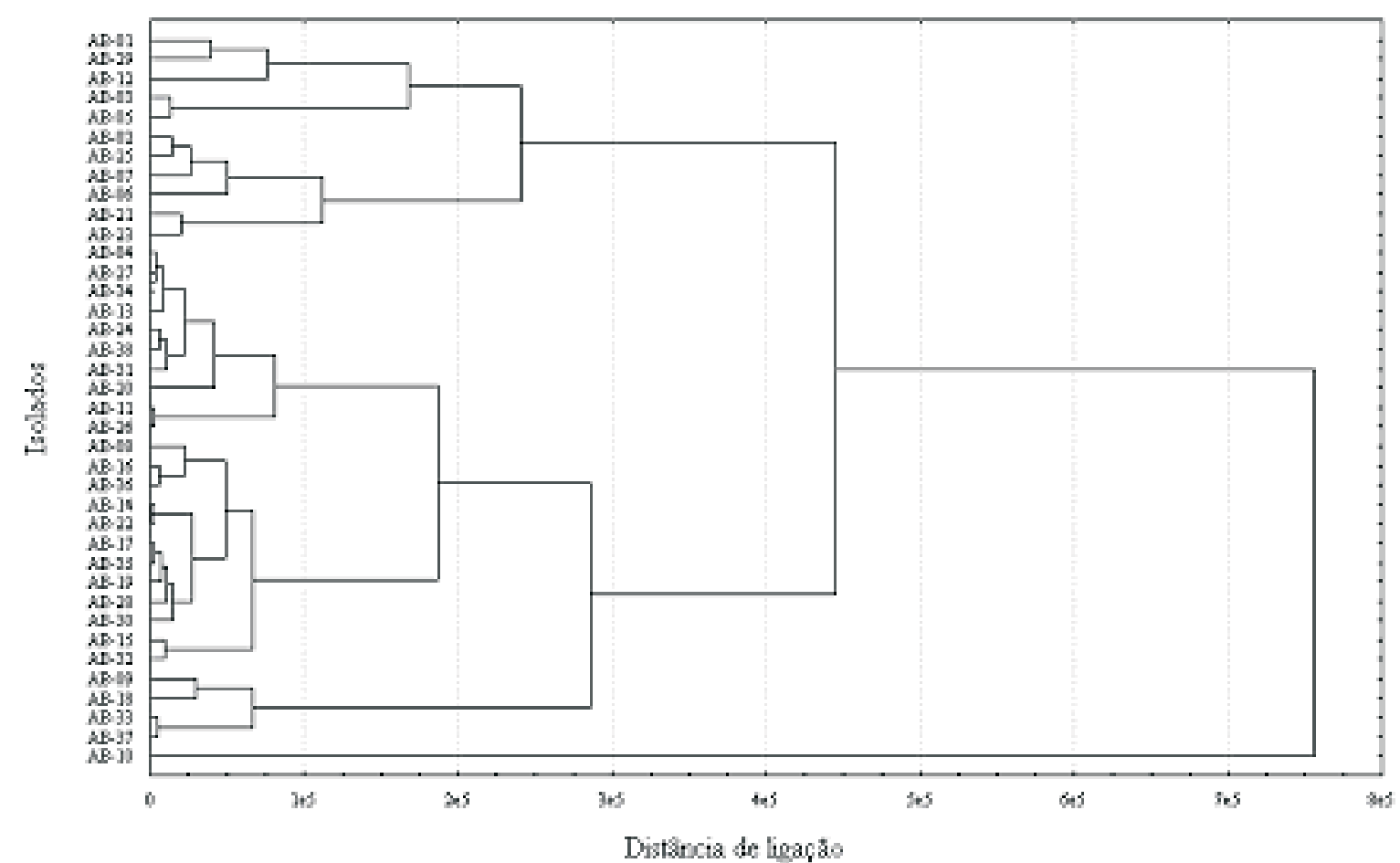

FIG. 1 - Agrupamento de 38 isolados de Alternaria brassicicola procedentes de diferentes áreas de plantio de crucíferas do Estado de Pernambuco, baseado na análise da distância Euclidiana por UPGMA, considerando os componentes epidemiológicos (PI, SEV, TPD e AACPD), as características fisiológicas (TCM, ESP e GER) e a sensibilidade ao fungicida iprodione (ICM).

1994; Sharma \& Tewari, 1998). As causas do surgimento da variabilidade entre os isolados do patógeno permanecem desconhecidas. No entanto, é provável que a variabilidade esteja associada à adaptação às diferentes espécies de crucíferas e/ou cultivares de uma mesma espécie, pois nos campos de produção do Agreste de Pernambuco são cultivadas diversas espécies e cultivares de crucíferas, com alta suscetibilidade à alternariose (IPA/CEAGEPE/EMATERPE, 1997; Azevedo et al., 2000). O fato de A. brassicicola possuir esporos multinucleados, pode gerar a manifestação de vários fenótipos, assim como a ocorrência de fenômenos como heterocariose e ciclo parassexual podem explicar, em parte, a variabilidade patogênica e fisiológica deste microrganismo.

\section{REFERÊNCIAS BIBLIOGRÁFICAS}

AZEVÊDO, S.S., MICHEREFF, S.J. \& MARIANO, R.L.R. Levantamento da intensidade da podridão negra e da alternariose do repolho no Agreste de Pernambuco e determinação do tamanho das amostras para quantificação dessas doenças. Summa Phytopathologica 26:299-306. 2000.

AZEVEDO, S.S., MICHEREFF, S.J. \& MARIANO, R.L.R. Epidemiologia comparativa da podridão negra e da alternariose do repolho no Agreste de Pernambuco. Fitopatologia Brasileira 27:1726. 2002.

BROWN, J.K.M. Surveys of variation in pathogen populations and their application to disease control. In: Jones, D.G. (Ed.) The Epidemiology of Plant Diseases. Dordrecht. Kluwer. 1998. pp.73102.
CAMPBELL, C.L. \& MADDEN, L.V. Introduction to Plant Disease Epidemiology. New York. John Wiley \& Sons. 1990.

CAMPBELL, R., LARNER, R.W. \& MADELIN, M.F. Notes on an albino mutant of Alternaria brassicicola. Mycologia 60:11221125.1968.

CHANGSRI, W. \& WEBER, G.F. Three Alternaria species pathogenic on certain cultivated crucifers. Phytopathology 53:643648. 1963.

CONN, K.L., TEWARI, J.P. \& AWASTHI, R.P. A disease assessment key for Alternaria blackspot in rapeseed and mustard. Canadian Plant Disease Survey 70:19-22. 1990.

DHINGRA, O.D. \& SINCLAIR, J.B. Basic Plant Pathology Methods. 2. ed. Boca Raton. Lewis Publishers. 1995.

ELLIS, M.B. Dematiaceous Hyphomycetes. Kew. Commonwealth Mycological Institute. 1971.

FUCHS, A. \& WAARD, M.A. Resistance to ergosterolbiosynthesis inhibitors. I. Chemistry and phenomenological aspects. In: Dekker, J. \& Georgopoulos, S.G. (Eds.) Fungicide Resistance in Crop Protection. Wageningen. Centre for Agricultural Publishing and Documentation. 1982. pp.71-86.

GRIFFIN, D.H. Fungal Physiology. 2. ed. New York. Wiley-Liss. 1994.

HAU, B. \& VALLAVIEILLE-POPE, C. Wind-dispersed diseases. In: Jones, D.G. (Ed.) The Epidemiology of Plant Diseases. Dordrecht. Kluwer. 1998. pp.323-347.

HUANG, R. \& LEVY, Y. Characterization of iprodione resistant isolates of Alternaria brassicicola. Plant Disease 79:828-833. 1995.

IPA/CEAGEPE/EMATER-PE. Sistema Integrado de Produção de 
Repolho (Brassica oleracea var. capitata) para o Estado de Pernambuco. Vitória de Santo Antão. Empresa Pernambucana de Pesquisa Agropecuária. 1997.

KATO, M., MIZUBUTI, E.S., GOODWIN, S.B. \& FRY, W E. Sensitivity to protectant fungicides and pathogenic fitness of clonal lineages of Phytophthora infestans in the United States. Phytopathology 87:973-978. 1997.

KENDALL, S.J. \& HOLLOMON, D.W. Fungicide resistance. In: Hutson, D.H. \& Miyamoto, J. (Eds.) Fungicidal Activity. New York. John Wiley \& Sons. 1998. pp.87-108.

LitTEll, R.C., MILliKen, G.A., STROUP, W.W. \& WOLFINGER, R.D. SAS System for mixed models. Cary. SAS Institute. 1996.

MARINGONI, A.C. Doenças das crucíferas (brócolis, couve, couvechinesa, couve-flor, rabanete, repolho e rúcula). In: Kimati, H., Amorim, L., Bergamin Filho, A., Camargo, L.E.A. \& Rezende, J.A.M. (Eds.) Manual de Fitopatologia: Doenças das Plantas Cultivadas. 3. ed. São Paulo. Agronômica Ceres. 1997. pp.315-324.

MCDONALD, B.A. \& LINDE, C. Pathogen population genetics, evolutionary potential, and durable resistance. Annual Review of Phytopathology 40:349-379. 2002a.

MCDONALD, B.A. \& LINDE, C. The population genetics of plant pathogens and breeding strategies for durable resistance. Euphytica 124:163-180. 2002b.

MILGROOM, M.C. The synthesis of genetics and epidemiology contributions of population biology in plant pathology. Journal of
Plant Pathology 83:57-62. 2001.

NETER, J., WASSERMAN, W. \& KUTNER, M.H. Applied Linear Statistical Models. $3^{\text {rd }}$ ed. Boston. Irwin. 1990.

PARLEVLIET, J.E. Components of resistance that reduce of epidemic development. Annual Review of Phytopathology 17:203222. 1979.

PAULA, H., MICHEREFF, S.J., COSTA, V.S.O., LARANJEIRA, D. \& OLIVEIRA, S.M.A. Variabilidad de aislamientos de Curvularia eragrostidis que causan atizonamiento de las hojas de ñame (Dioscorea cayennensis) en Pernambuco, Brasil. Boletín Micológico 11:85-92. 2000.

ROTEM, J. The Genus Alternaria. St. Paul. APS Press, 1994.

SHANER, G. \& FINNEY, R.E. The effect of nitrogen fertilization on the expression of slow-mildewing resistance in Knox wheat. Phytopathology 67:1051-1056. 1977.

SHARMA, T.R. \& TEWARI, J.P. RAPD analysis of three Alternaria species pathogenic to crucifers. Mycological Research 102:807814. 1998.

SUMMERS, R.W., HEANEY, S.P. \& GRINDLE, M. Studies of a dicarboximide resistant heterokaryon of Botrytis cinerea. Proceedings, Brighton Crop Protection Conference, Brighton, England, 1984. pp.453-458.

VERMA, P.R. \& SAHARAN, G.S. Monograph on Alternaria Diseases of Crucifers. Saskatoon. Minister of Supply and Services Canada. 1994. 